\title{
Brincoquímica: Uma Ferramenta Lúdico- Pedagógica para o Ensino de Química Orgânica
}

\begin{abstract}
João R. de Freitas Filho
Rinnely Cecília Lins de Melo

Juliano C. Rufino Freitas

Ladjane Pereira da Silva R. de Freitas

Jucleiton José R. de Freitas

Resumo

O uso de atividades lúdicas no ensino de Química está associado à busca por melhorias no processo de ensino e aprendizagem. Diante deste contexto, a construção e aplicação de jogos didáticos para o ensino de Química se configura como uma das inúmeras alternativas viáveis para a promoção de tais melhorias. Esse artigo relata uma experiência que utiliza jogos como metodologia de ensino na aprendizagem de Química Orgânica, para auxiliar o ensino de isomeria e funções oxigenadas. Antes da aplicação dos jogos foi ministrada uma aula teórica sobre os assuntos em questão e logo após foi realizado um teste de sondagem para avaliar o nível da aprendizagem dos estudantes. Os resultados obtidos foram promissores e demonstram que o uso de jogos no ensino de Química se configura como ferramenta pedagógica de alto potencial didático, e que deve ser mais explorado em prol da qualidade do ensino de Química.
\end{abstract}

Palavras-chave: Atividade lúdica, ensino de química, sala de aula.

\section{Abstract \\ Brincoquímica: a tool for teaching playful-teaching of organic chemistry}

The games an innovative methodology for teaching and engaging in more enjoyable and interesting, since the lack of motivation is the main cause of alienation among students, almost always brought about by the methodology used by the teacher to pass the contents. This paper reports an experiment that uses games as a methodology of teaching in learning organic chemistry, to assist the teaching of isomerism and oxygen function. Before the implementation of the game was given a theoretical lesson on the subject in question and soon after was conducted a test of survey to evaluate the level of learning. The results were promising and show that the use of games in teaching Chemistry is configured as a pedagogical tool for teaching high potential, and should be further explored for the quality of the teaching of chemistry.

Keywords: Playful activity, chemistry teaching, classroom.

\section{Introdução}

A prática, do ensino de Química Orgânica no Ensino Médio, em sala de aula, consiste na transmissão-recepção de conhecimentos que, muitas vezes, não são compreendidos. Para 
estimular e resgatar o interesse dos estudantes pelas aulas de química é fundamental que o professor busque metodologias diferenciadas que o auxiliem no processo de ensino e aprendizagem (SOARES et al., 2003). Segundo esses autores, o desenvolvimento de estratégias modernas e simples, utilizando experimentos, jogos e outros recursos didáticos, é recomendado para dinamizar o processo de aprendizagem em Química.

Atualmente, existe uma preocupação entre os pesquisadores na área de ensino de Química para que possam ser apresentadas novas metodologias, que busquem levar aos estudantes um ensino mais dinâmico e, nesse contexto, está inserida a utilização de atividades lúdicas. Nessa perspectiva, alguns trabalhos envolvendo o uso de atividades lúdicas no ensino de Química têm sido publicados na literatura brasileira (SOARES et al., 2003; OLIVEIRA e SOARES, 2005; SOARES e CAVALHEIRO, 2006; GIACOMINI et al., 2006).

O lúdico apresenta dois elementos que o caracterizam: o prazer e o esforço espontâneo, além de integrarem as várias dimensões do estudante, como a afetividade, o trabalho em grupo e das relações com regras pré-definidas. O mesmo deve ser inserido como impulsor nos trabalhos escolares. Os jogos são caracterizados como um tipo de recurso didático educativo que podem ser utilizados em momentos distintos como na apresentação de um conteúdo, ilustração de aspectos relevantes ao conteúdo, avaliação de conteúdos já desenvolvidos e como revisão ou síntese de conceitos importantes (CUNHA, 2004).

De acordo com Melo (2005), vários estudos relacionados com atividades lúdicas veem comprovar que o jogo, além de ser fonte de prazer e descoberta para o estudante é a tradução do contexto sócio - cultural - histórico refletido na cultura, podendo contribuir significantemente para o processo de construção do conhecimento do aluno como mediadores da aprendizagem. Ainda segundo Melo (2005) o lúdico é um importante instrumento de trabalho, o mediador, no caso o professor deve oferecer possibilidades na construção do conhecimento, respeitando as diversas singularidades. Essas atividades quando bem exploradas oportunizam a interlocução de saberes, a socialização e o desenvolvimento pessoal, social, e cognitivo.

Ao criar ou adaptar um jogo ao conteúdo escolar, segundo Borges e Schwarz (2005), ocorrerá o desenvolvimento de habilidades que envolve o indivíduo em todos os aspectos: cognitivos, emocionais e relacionais. Tem como objetivo torná-lo mais competente na produção de respostas criativas e eficazes para solucionar os problemas. Ser competente implica em saber mobilizar de forma criativa e eficaz as habilidades, nas quais os conhecimentos, valores e atitudes são usados de forma integrada frente às necessidades impostas pelo meio. As habilidades se constroem e manifestam na ação, a qual se aprimora pela prática, levando à reconstrução do conhecimento.

Em contrapartida, Piaget (1975) nos diz que os jogos em si não carregam a capacidade de desenvolvimento conceitual, porém considera que eles acabam suprindo certas necessidades e 
funções vitais ao desenvolvimento intelectual e consequentemente, da aprendizagem. De acordo com essa visão, o lúdico, a brincadeira, o jogo e tudo o mais envolvido com o ludismo, representa um acesso a mais no desenvolvimento cognitivo, ao abastecer, enriquecer e diversificar as possibilidades experimentais e táteis do sujeito.

Vários pesquisadores da área de ensino de Química, entre eles, Soares e Cavalheiro (2006), Crute e Myers (2007) e Costa (2007) têm utilizado o jogo pedagógico como ferramenta no processo de ensino aprendizagem e mostrado que esse atrai o interesse dos estudantes, adiciona motivação extra ao processo de aprendizagem, contribui para superar as dificuldades iniciais que os estudantes encontram com os conceitos químicos e cria oportunidades para o docente identificar os erros conceituais e corrigi-los imediatamente, durante sua aplicação. Esses autores observaram também que durante a aplicação dos jogos pedagógicos os estudantes se envolveram na atividade buscando em todas as etapas do jogo novas ideias e conceitos, fato que não ocorre em aulas expositivas - dialogadas.

Segundo Soares (2008), o livro Jogos para o ensino de química: teoria, métodos e aplicações, que tem sido uma boa referência para aqueles que desejam pensar no lúdico para sala de aula, bem como um referencial importante para formação de professores nos cursos de Graduação, Licenciatura ou formação continuada.

De acordo com os autores Santos e Michel (2009), o jogo de baralho baseado nas regras da Sueca que tem por objetivo trabalhar as relações entre estrutura e força de ácidos de Arrhenius por meio da constante de ionização, é um bom exemplo da aplicação jogos/lúdicos. Por outro lado, no mesmo ano Benedetti Filho et al. (2009), propuseram os jogos de palavras cruzadas para revisar e exercitar conceitos, definições e episódios históricos da Teoria Atômica.

No ano de 2012, foi publicada uma pesquisa sobre jogos no ensino de química na revista Química Nova na Escola pelo autor Nunes. Com este artigo o autor pretende contribuir, trazendo alguns referenciais teóricos e aspectos pedagógicos que devem ser levados em consideração quando se pretendem desenvolver atividades com jogos didáticos nas aulas de química.

Ferreira e do Nascimento (2013) relata a utilização de um jogo didático (ludo) como instrumento de avaliação da aprendizagem em vez dos instrumentos tradicionais (prova escrita, pesquisas etc.) e verificar o desempenho e a satisfação dos estudantes surdos em relação a essa forma de avaliar na disciplina química

Mediante o exposto, o objetivo deste trabalho foi relatar uma experiência que utiliza jogos como metodologia de ensino na aprendizagem de Química Orgânica, de modo a auxiliar o ensino de isomeria e funções oxigenadas a partir da temática Química dos Lipídios.

\section{Focalizando a Proposta Metodológica}




\section{Contexto da pesquisa}

A pesquisa foi realizada em uma turma constituída por 30 estudantes, do 3 o ano do Ensino Médio de uma Escola Pública situada na cidade de Barreiros/PE. A turma era bastante heterogênea. Alguns trabalhavam devido o baixo poder aquisitivo de seus pais. A abordagem metodológica da pesquisa foi qualitativa, uma vez que os dados foram coletados em um grupo de estudantes antes (pré-teste) e depois (pós-teste) da aplicação dos jogos.

\section{Momento em sala de aula}

Primeira aula - Aula expositiva dialogada sobre funções oxigenadas e isomeria.

Inicialmente os estudantes tiveram uma aula sobre ácidos carboxílicos e isomeria, mas especificamente isomeria geométrica, com a utilização dos seguintes recursos: livro didático, lousa e pincel e modelo molecular. A aula teve duração de 100 minutos.

Segunda aula - Leitura de imagem e elaboração de texto a partir da temática Química dos lipídios.

Esta aula teve início com a apresentação de uma imagem (figura 1) a ser observada e discutida pelos estudantes. A imagem foi projetada em data-show e tratava da temática relacionada com a química dos lipídios, mas especificamente, da gordura trans. A partir daí, os estudantes tentaram produzir um pequeno texto, de no máximo quinze linhas, sobre o que observaram na figura. Este momento teve como objetivo levantar os conhecimentos dos estudantes a respeito da temática - Química dos lipídios, correlacionando com as funções oxigenadas e o fenômeno de isomeria. Esta aula teve duração de 50 minutos.

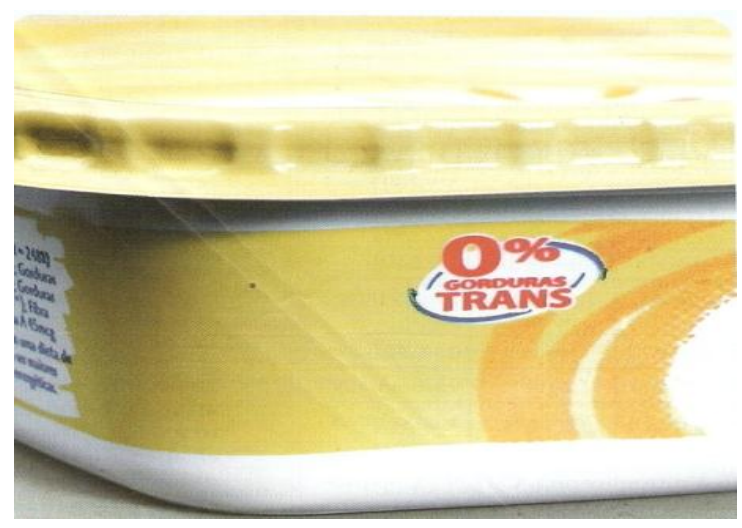

Figura 1 - Imagem da margarina delícia consumida pelos estudantes.

(Fonte: Elaboração própria)

Terceira aula - Painel integrado versus painel interativo.

Nesta aula, foi proposto a eles à leitura do texto: Óleos e Gorduras: aspectos gerais, em grupos, lançando mãos da estratégia de ensino - painel integrado - e em seguida a construção de um painel interativo. $\mathrm{O}$ texto mostra através de vários exemplos os aspectos gerais de óleos e gorduras, a 
relação com os ácidos graxos, demonstrações de estruturas, figuras, algumas reações orgânicas e o percentual de gordura trans em alguns alimentos. As etapas utilizadas neste momento foram as seguintes:

Etapa 1 : Foi solicitado que os estudantes formassem quatro grupos, cada grupo com seis ou sete estudantes. Os estudantes que compunha cada grupo foram enumerados com os números 1, 2, 3, 4,5 e 6.

Etapa 2 : Distribuição dos textos para os grupos e após a leitura do material, foi solicitado que os componentes dos grupos fizessem uma síntese do texto lido.

Etapa 3 : Todos os estudantes de número 1 formaram um novo grupo e assim sucessivamente, ou seja, foi feito o cruzamento entre os diferentes membros dos diferentes grupos de tal forma que, em cada novo grupo tenham representantes de todos os outros primeiros grupos e portanto todos os textos discutidos para elaboração de uma nova síntese.

Etapa 4 : Apresentação dos resultados das sínteses em plenária.

Etapa 5 : Construção de um painel interativo.

Estas estratégias de ensino foram desenvolvidas em duas aulas. Cada aula teve duração de 50 minutos. Para nortear a leitura dos textos, perguntas específicas foram apresentadas aos estudantes para que eles pudessem gerar discussões no grupo. Nessas duas aulas, o professor organizou as discussões e sistematizou as falas dos estudantes em um painel interativo para que ao final fizesse uma organização dos conceitos.

Quarta aula - Aplicação de um pré-teste

O pré-teste aplicado versava sobre questões de isomeria e funções oxigenadas. Estas questões tiveram como objetivo avaliar os conhecimentos de funções oxigenadas e isomeria apresentado pelos estudantes e correlacionar com a química dos lipídios. O pré-teste constitui-se das seguintes questões: 1) O que são ácidos carboxílicos? 2) O que são ácidos graxos? 3) Qual o grupo funcional presente nos ácidos carboxílicos e nos ácidos graxos? 4) Os ácidos carboxílicos reagem com alcoóis formando o que? 5) Qual a principal característica de um éster? 6) As cadeias carbônicas das moléculas de óleos são mais saturadas ou insaturadas? 7) Qual a diferença entre óleos e gorduras? 8) Quais funções orgânicas são comumente encontradas nas moléculas presentes em gorduras trans? 9) O que são isômeros? 10) O que são isômeros trans? 11) Qual a diferença entre isômero Cis e isômeros trans? 12) Nos alquenos isoméricos espacialmente, as duplas ligações podem existir de duas formas geométricas diferentes, quais? A aula teve duração de 50 minutos.

\section{Quinta aula - Aplicação dos jogos: Brincoquímica}

Neste momento os grupos das etapas anteriores foram desfeitos e formados três novos grandes grupos constituídos cada um, por 10 alunos. Cada grupo foi organizado em um local da 
sala, onde propusemos a cada um, uma brincadeira (jogo): grupo 1 - Quimarelinha (genérico da amarelinha), grupo 2 - Quimigude (genérico do jogo de bola de gude) e grupo 3 - Química quente (genérico da brincadeira batata quente). No jogo Química quente cada grupo ficou incumbido de criar e apresentar uma paródia utilizando conceitos de química sobre os seguintes conteúdos: Isomeria, Isomeria Geométrica, Ácidos carboxílicos, Ésteres, Gordura Trans, Lipídios, Ácido Graxos (extra-classe). As paródias elaboradas foram entregues para avaliação e correção pelos professores de possíveis erros conceituais antes da apresentação aos colegas. Cada grupo deveria corrigir os aspectos apontados antes da apresentação.

Quimarelinha: Para desenvolver esta brincadeira, foi montada uma amarelinha no piso da sala de aula. Esta se constituiu de 8 casas e em cada casa uma pergunta sobre a temática discutida anteriormente no painel integrado. A brincadeira iniciou com estudante, jogando uma pedrinha na primeira casa e se acertasse a pergunta pulava de um pé só na casa número 2 e nas casas seguintes e pegava a pedrinha de volta seguindo o jogo. Caso não acertasse daria a vez a outro estudante (jogador) participante. Em cada casa continha uma pergunta, relacionada com o texto. A brincadeira consistiu em estimular o equilíbrio do estudante e questioná-lo sobre os conceitos estudados. As perguntas nas casas foram as seguintes:

1- Onde são encontradas as gorduras trans?

2- Qual o grupo funcional presente nos ácidos carboxílicos e nos ácidos graxos?

3- Quais funções orgânicas são comumente encontradas nas moléculas presentes em gorduras trans?

4- O que são isômeros trans?

5- Quais os ácidos graxos essenciais?

6- Os ácidos carboxílicos reagem com alcoóis formando o que?

7- 0 que são ácidos graxos?

8- O que são ácidos carboxílicos??

Quimigude: 0 grupo 2 participou da brincadeira jogando bola de gude num quadrado de isopor, no qual foi desenhado o anel benzênico. Em cada extremidade continha uma bola de gude e ao seu lado, uma bandeirinha, que continha uma pergunta. As perguntas nas bandeirinhas foram enumeradas de 1 a 6 . Cada estudante (jogador) deve tentar acertar a bolinha jogada pelo anterior e, assim, ganhá-la para si. Após a jogada, só ficaria com a bolinha do adversário aquele que acertasse a pergunta, caso contrário saía do jogo. O jogo começa com uma bolinha grande colocada no chão, em espaço livre. O primeiro jogador tenta acertá-la, o segundo mira a bolinha do primeiro e assim por diante. $O$ jogo só acaba quando os participantes quiserem.

As perguntas proposta neste jogo foram: 
1- O que são isômeros Cis?

2- Qual a diferença entre óleos e gorduras?

3- O que são isômeros?

4- Qual a principal característica de um éster?

5- As cadeias carbônicas das moléculas de óleos são mais saturadas ou insaturadas?

6- Os triacilgliceróis possuem cadeias carbônicas saturadas ou insaturados? São óleos ou gorduras?

Química quente: Os componentes do grupo 3, formaram um círculo e alguém ficou no centro. A pessoa do centro é responsável pela música. Eles passaram uma bola, de mão em mão, com envelopes colados na mesma também com perguntas sobre o texto estudado. As perguntas foram enumeradas de 1 a 8 . Ao passar a bola de mão a mão os estudantes cantavam uma música compostas por eles sobre química. Quando o participante do meio do círculo batia palma à música parava e quem estivesse segurando a bola destacava uma pergunta de 1 a 8 , e tentava responder corretamente, se acertasse continuava no jogo, caso contrário sairia do círculo e o jogo continuava com os estudantes restantes. As perguntas deste jogo foram as seguintes:

1- Os ácidos carboxílicos são substâncias polares ou apolares?

2- O que são ácidos graxos?

3- Os ácidos carboxilicos reagem com álcoois formando o que?

4- Qual a principal característica de um éster?

5- O que são ácidos carboxílicos?

6- Qual a diferença entre isômero Cis e isômeros trans?

7- Nos alquenos isoméricos espacialmente, as duplas ligações podem existir de duas formas geométricas diferentes, quais?

8- A produção de margarina é feita atualmente por que tipo de processo?

Esta etapa dos jogos foi desenvolvida em duas aulas, cada aula com duração de $50 \mathrm{~min}$. As questões utilizadas nos jogos serviram para avaliar conhecimentos gerais sobre a temática e também sobre conteúdos de Química Orgânica.

Sexta aula - Aplicação de um pós-teste

Após aplicação dos jogos os estudantes responderam a um pós-teste, feito para avaliar questões de aprendizagem. O pós-teste contenha as mesmas questões usado no pré-teste. Este momento teve duração de 50 minutos.

Sétima aula - Avaliação das atividades realizadas pelos estudantes 
A última aula foi caracterizada pela entrega de fichas de avaliação aos estudantes contendo afirmações com respeito à atividade desenvolvida. Os questionamentos estão descrito na tabela 1 a seguir:

Tabela 2-Questionamentos sobre a aplicação do brincoquímica.

QUESTÕES

RESPOSTAS

\begin{tabular}{l} 
SIM NÃO \\
\hline
\end{tabular}

1- Os jogos auxiliaram na fixação do conteúdo?

2- A aplicação dos jogos ajudou a melhorar os

relacionamentos por ser uma atividade desenvolvida em grupo?

3- A metodologia adotada é melhor do que uma aula expositiva?

4- Depois do jogo aumentou seu interesse em estudar mais o conteúdo da disciplina?

5- O jogo aplicado foi de fácil compreensão?

5- Trabalhando o conteúdo em grupo o jogo foi possível sanar algumas dificuldades?

\section{Analisando os Resultados Discutindo os textos elaborados pelos estudantes}

Após aula expositiva, houve necessidade de contextualizar o conteúdos trabalhados anteriormente, através da temática Química dos lipídios, para isso lançamos mãos de uma embalagem de uma margarina com a descrição "0\% gordura TRANS" (Figura 1, metodologia). A partir da imagem projetada, os estudantes foram questionados, individualmente, sobre a figura e em seguida produziram um pequeno texto, com no mínimo 12 linhas, sobre o que estava sendo destaque na embalagem. Posteriormente, são transcritos alguns trechos escritos pelos estudantes.

Aluno (A): "Nós consumidores, devemos sempre quando formos às compras olharmos sempre as embalagens dos produtos onde estão localizadas as informações."

Aluno (B): "A gordura é prejudicial à saúde, pois encontramos essas gorduras trans, na carne, pipocas, leite, margarina, milho, soja trigo integral entre outros."

Aluno (C): "A gordura trans em excesso faz mal à saúde. Os médicos não recomendam o uso de produtos que contém esse tipo de gordura."

R. B. E. C. T., vol 8, núm. 1, jan-abr.2015 ISSN - 1982-873X

DOI: Em andamento 
Aluno (D): "A gordura trans é uma gordura que é prejudicial a nossa saúde. Ela pode causar alta taxa de colesterol, pressão alta e os alimentos com gordura trans pode causar obesidade."

Diante do que foi escrito pelos estudantes, nota-se que muitos deles ressaltaram a questão do risco que o consumo de gordura trans causa e a atenção de ler os rótulos das embalagens de alguns produtos, citando até alguns deles. Por outro lado, percebem-se à confusa concepção do conceito de gordura trans:

Aluno (E): "A gordura trans é diferente da gordura normal."

Aluno(F): "Os alimentos que possuem esta gordura são muitas vezes aconselhados a consumir em pequena quantidade... alimentos que possuem muito açúcar."

Aluno (G): "alimentos sem gordura trans são indicados para pessoas que tem excesso de peso."

Em todos os textos analisados, observou-se que a gordura trans é colocada como uma vilã para a saúde, muitos deles sabem quais os alimentos que contém este tipo de gordura, mas desconhecem a origem e algumas reações sofridas pela mesma. Em seguida estão descritas outras transcrições dos estudantes sobre gordura trans.

Aluno (H): "A gordura trans é um tipo de gordura saturada que prejudicam a saúde."

Aluno (I): "A gordura trans é a transformação do óleo vegetal em gordura sólida."

Concluindo a análise, nas transcrições abaixo, percebem-se algumas concepções erronias de alguns estudantes:

Aluno (J) : “É uma gordura sem sal...quando se tira o sal do alimento deixa-o sem gordura."

Aluno (L) : "A gordura trans é o mesmo que gordura hidrogenada."

\section{Discutindo o texto Óleos e Gorduras: aspectos gerais por meio de Painel integrado}

A turma foi dividida em quatro grupos (figura 2) e os textos foram distribuídos aos grupos formados, depois da leitura do texto, os estudantes fizeram uma síntese do texto. Estes grupos foram defeitos e outros grupos foram formados. Do novo grupo formado foi construindo um novo texto. O texto final foi apresentado em plenária. 


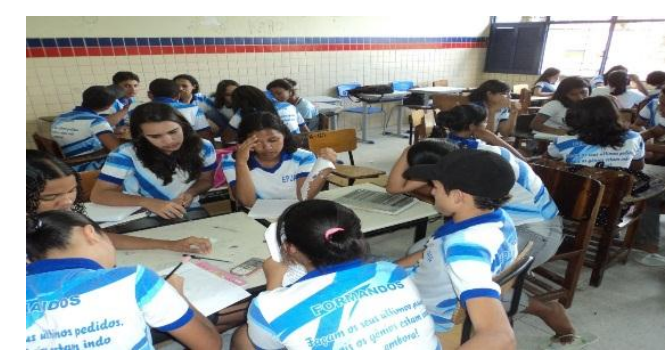

Figura 2. Formação dos grupos e leitura de texto proposto "painel integrado".

(Fonte: Elaboração pelos autores deste artigo)

Em seguida, são transcritos trechos da síntese final dos estudantes:

As gorduras trans podem ser encontradas...

Os ácidos essenciais são ...

As gorduras são obtidas através de um processo de...

Os ácidos graxos saturados possuem...

Os triacilgliceróis são encontrados...

Os ácidos carboxilicos reagem com álcool e forma...

A função principal na caracterização de uma gordura é...

As diferenças entre óleo e gordura são...

Os ácidos que seu consumo diminuem as doenças cardíacas...

As gorduras saturadas são óleos ou gorduras...

A partir dos textos finais os estudantes construíram um novo painel interativo (figura 3 e 4)

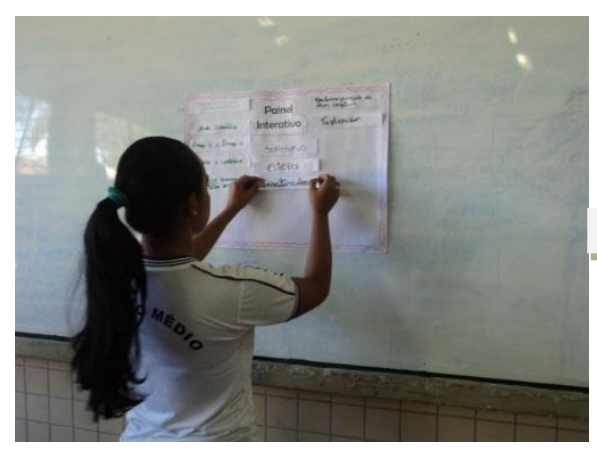

Figura 3. Estudante montando o

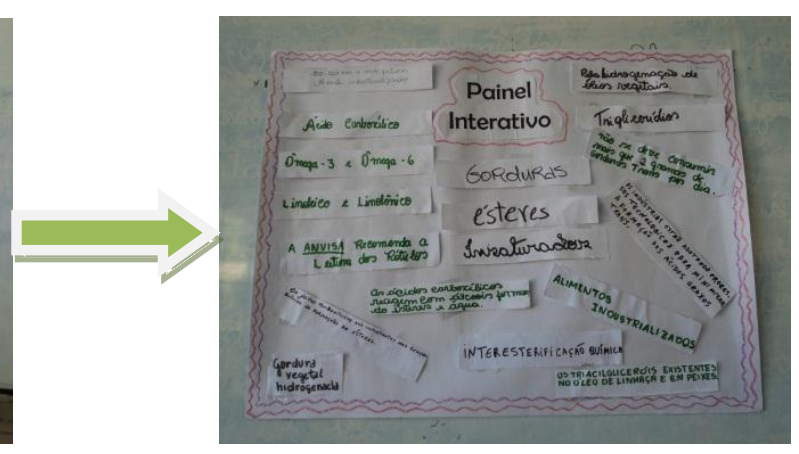

Figura 4. Painel interativo Construídos. painel interativo.

(Fonte: Elaboração pelos autores) 


\section{Discutindo a elaboração e aplicação do pré-teste}

$\mathrm{Na}$ elaboração das questões do pré-teste foram levadas em consideração algumas sugestões de diversos autores (MOREIRA e MASINI, 2002, MAGALHÃES HILL e HILL, 2002; PARDAL e CORREIA, 1995) relacionadas com a redação das questões. Priorizou-se neste trabalho questões de resposta aberta uma vez que estas permitiu um leque de informação rica e detalhada. Pela aplicação do pré-teste, com questões abertas, levantaram-se informações sobre o que os estudantes conheciam a respeito de ácidos carboxílicos e derivados, isomeria e lipídios, mas especificamente, ácidos graxos.

Para as questões propostas, definiram-se quatro categorias: "Resposta Correta (RC)", "Resposta Incompleta (RI)", "Resposta Errada (RE)" e "Não Respondeu (NR)". A tabela 2 sumariza os resultados obtidos.

Tabela 2 - Resultados obtidos pelos estudantes no pré-teste.

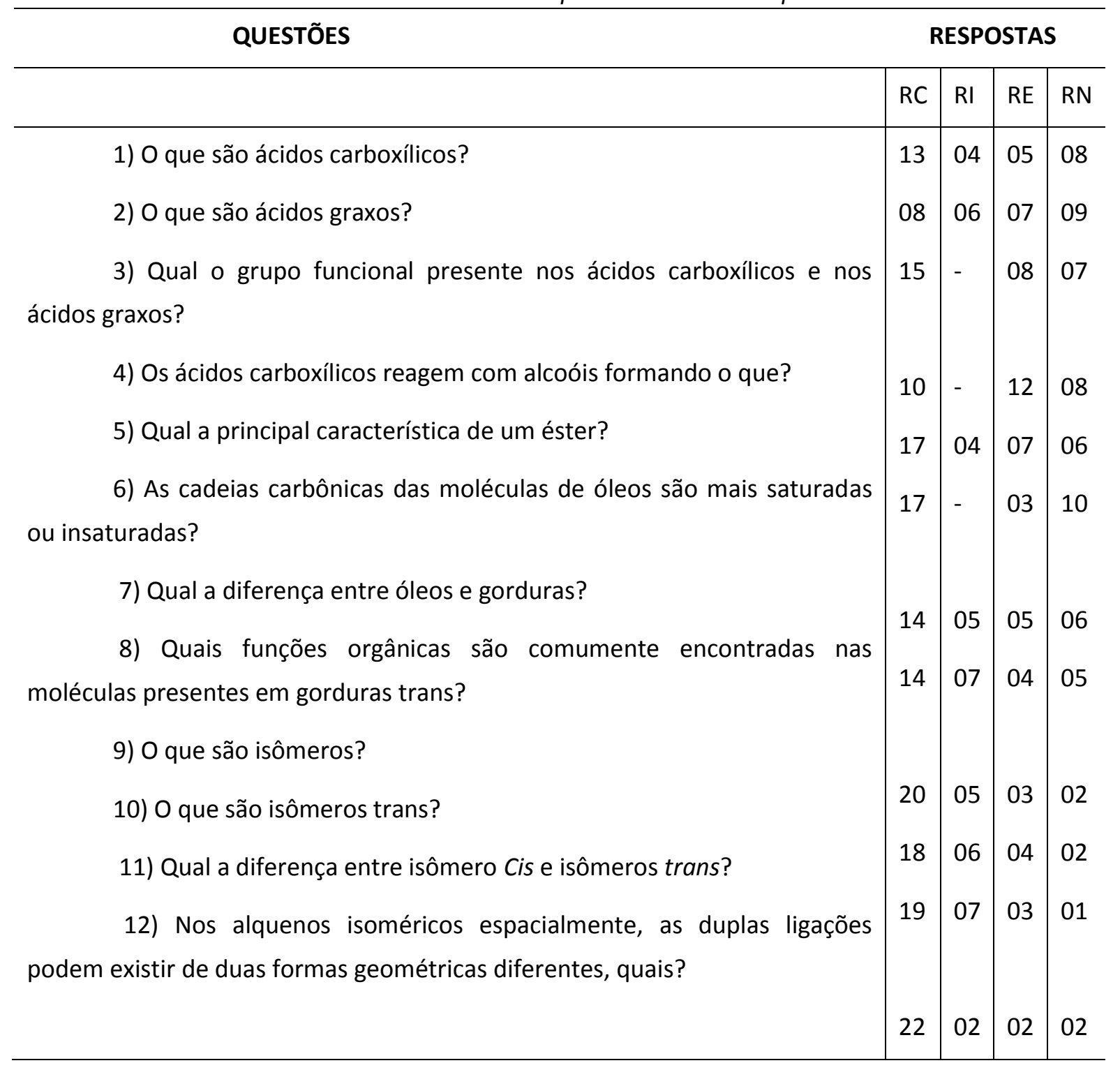


De acordo com os resultados expressos na tabela 2, percebe-se que $50 \%$ dos estudantes compreendem bem questões relacionadas aos conceitos de ácidos carboxílicos, derivados e ácidos graxos (questões 1 a 5), e a óleos e gorduras (questão 7 e 8). O fenômeno de isomeria e sua classificação (questão 9-12) foi respondida corretamente por $65 \%$ dos estudantes, sendo que $13 \%$ erraram as questões, $10 \%$ não responderam e $12 \%$ deram resposta incompletas.

\section{Discutindo a aplicação das atividades lúdicas}

Durante a aplicação do Brincoquímica, pôde-se perceber um maior entusiasmo por partes dos estudantes, por ser um recurso pedagógico não utilizado frequentemente pelo docente.

Segundo Borges e Schwarz (2005), ao adaptar um jogo ao conteúdo escolar, ocorrerá o desenvolvimento de habilidades envolvendo o estudante em todos os aspectos: cognitivos, emocionais e relacionais. Assim o estudante implicará em saber mobilizar de forma criativa e eficaz as habilidades, nas quais os conhecimentos, valores e atitudes são usados de forma integrada frente às necessidades impostas pelo meio. As habilidades se constroem e manifestam na ação, a qual se aprimora pela prática, levando à reconstrução do conhecimento.

Durante o desenvolvimento dos jogos, observou-se o desenvolvimento e o interesse de cada estudante individualmente. Os estudantes que participaram da primeira brincadeira (Figura 5) tiveram um pouco de dificuldade em relação ao equilíbrio, mas ao mesmo tempo se preocupavam em responder as questões de forma correta para vencer o jogo. A brincadeira estimulou os estudantes a construir conceitos além de estimular a habilidade de equilíbrio. Convém destacar que nem sempre alguns estudantes conseguiam responder sempre corretamente a determinada pergunta. Nesta brincadeira sempre tinha perguntas extras. Perguntas essas que eram trocadas pelas outras no decorrer da brincadeira. Os estudantes questionavam sobre algumas perguntas, pois não tinham conhecimento sobre seu contexto. 


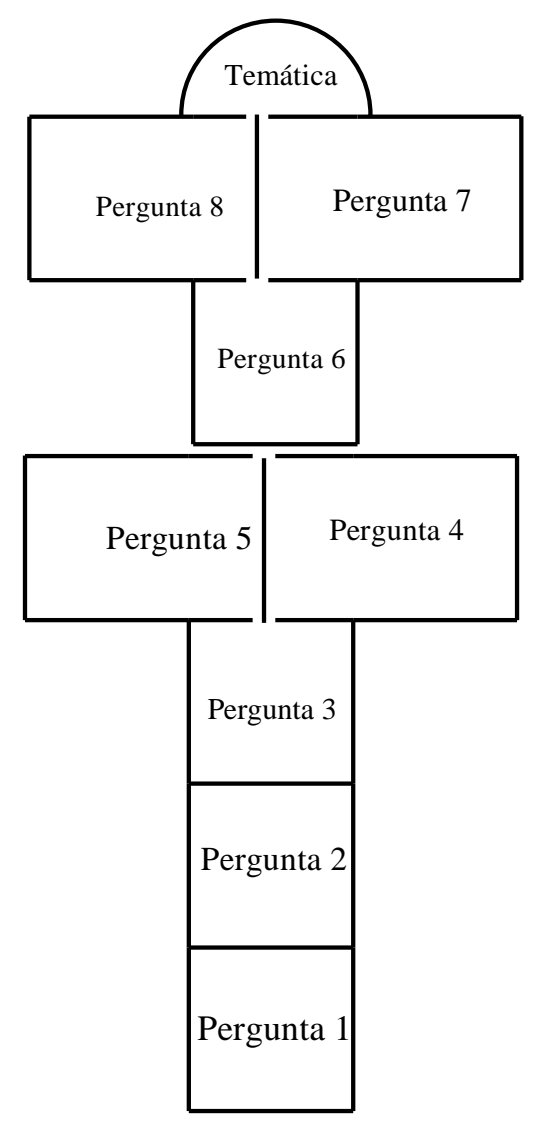

Figura 5: Formato adotado para Quimarelinha.

(Fonte: Elaboração própria)

O grupo que participou do segundo jogo (Figura 6) foi o que mais interagiu entre si, isto por que era formada por meninos, e os meninos têm costume de brincar de bola de gude. A intenção da brincadeira era estimular os estudantes a responder de forma rápida e se concentrarem nas perguntas, durante o desenvolvimento da brincadeira os estudantes costumavam questionar os colegas das outras brincadeiras e quando erravam alguma pergunta ficavam furiosos por não conseguir a bolinha do adversário. Desta forma foi relevante a participação dos estudantes, pois mesmo depois de duas aulas tiveram vontade de concluir o jogo. Esta brincadeira motivou de forma satisfatória os integrantes do grupo e muitos deles comentaram que se o professor usasse sempre uma metodologia diferente em cada aula ministrada, eles aprenderiam mais e melhor. 


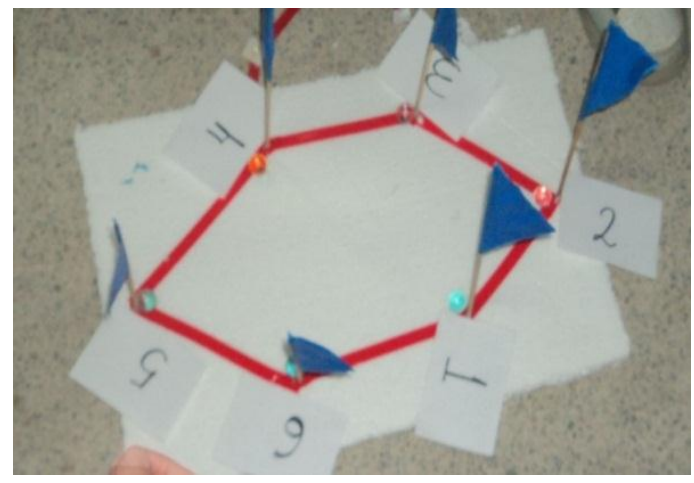

Figura 6 - Esquema do jogo Quimigude.

(Fonte: Elaboração própria)

Os estudantes que formaram o grupo da terceira brincadeira (Figura 7) desenvolveram muito bem e tornaram a brincadeira bem rápida, se concentraram e coordenaram os movimentos ao ritmo da fala, escolheram uma paródia envolvendo a química e brincaram de forma descontraída. Cada estudante que errou a pergunta abandonou o jogo. Como nos outros jogos a reação dos estudantes era sempre a mesma, saber as respostas para continuar no jogo, nesta, a competição terminou com duas meninas e as duas sempre ficavam empatadas mostrando assim que as duas sabiam responder as perguntas, para o desempate os outros colegas participaram.

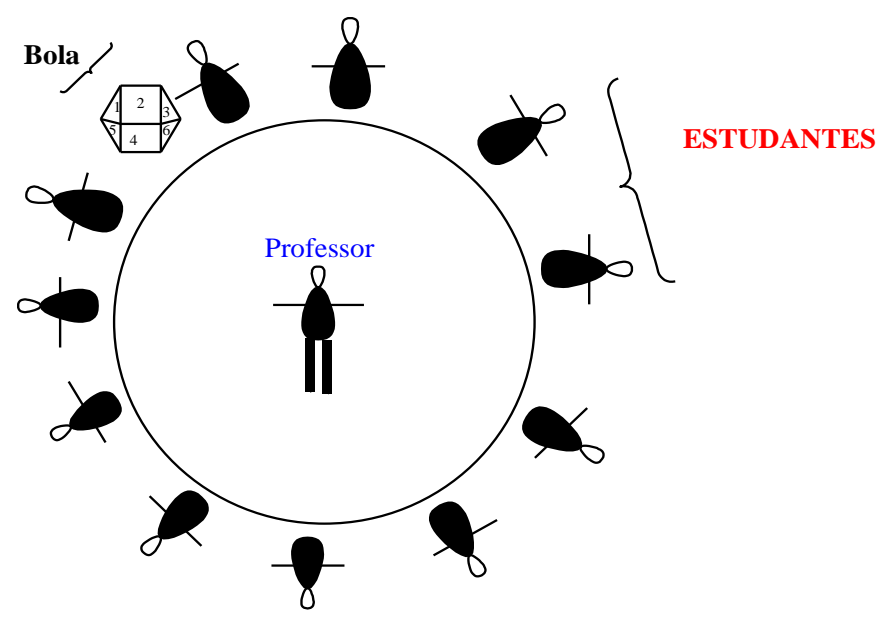

Figura 7. Formato adotado para Química quente.

(Fonte: Elaboração própria)

Após a aplicação das atividades lúdicas, os estudantes produziram alguns textos sobre ácidos graxos e gorduras trans. Nas produções, os estudantes já escreviam corretamente o conceito de ácido carboxílico, a diferença entre ácidos carboxílicos e ácidos graxos, por exemplo:

Aluno (C): "ácidos graxos também são ácidos carboxílicos só que de cadeia longa e são encontrados nas gorduras." 
Também conseguiam reconhecer os ácidos carboxílicos no cotidiano. O conceito que muitos tinham sobre a função orgânica "ácido carboxílico" fugia da realidade, pois só eram cobrados, em aulas convencionais, o grupo funcional, as estruturas e a nomenclatura. Muitos dos estudantes mesmo com dificuldade nos nomes dos compostos perceberam que os ácidos graxos podem ser classificados em saturados e insaturados e dependendo dessas características são divididos em óleos e gorduras.

Aluno (F): "As gorduras são ácidos saturados e os óleos são insaturados."

Aluno (I): "Os óleos são líquidos e as gorduras sólidas"

Aluno (D): "Quando as pessoas fazem exames de triglicerídeos é para saber o teor de gordura no sangue."

Aluno (B): "Os lipídeos são gorduras que vem de animais e vegetais."

Dessa forma, observou-se que o jogo auxiliou os estudantes na aprendizagem em relação aos conceitos de ácidos carboxílicos/derivados, isomeria/classificação, além de ácidos graxos, gorduras trans, como também, no desenvolvimento lógico e estratégico para vencer o jogo.

Para avaliar a contribuição do jogo na melhora do desempenho dos estudantes, foram aplicados pós-testes referentes ao conteúdo abordado. Ao comparar os resultados obtidos nesse teste com o pré-teste, pôde-se perceber que o jogo ajudou a melhorar o desempenho dos estudantes com relação ao conhecimento sobre ácidos carboxílicos, derivados de ácidos, isomeria, isomeria geométrica, ácidos graxos, gorduras/ óleos e lipídios. Os resultados estão sumarizados na tabela 3.

Tabela 3. Resultados obtidos pelos estudantes após

aplicação do pós-teste.

\begin{tabular}{l|l|l|l|l}
\hline \multicolumn{1}{c}{ QUESTÕES } & RC & RI & RE & RN \\
\hline 1) O que são ácidos carboxílicos? & 24 & 4 & 1 & 1 \\
2) O que são ácidos graxos? & 21 & 4 & 3 & 2 \\
3) Qual o grupo funcional presente nos ácidos carboxílicos e nos & 28 & - & - & 2 \\
ácidos graxos? & & & & \\
4) Os ácidos carboxílicos reagem com alcoóis formando o que? & 19 & - & 8 & 3 \\
5) Qual a principal característica de um éster? & 20 & 4 & 4 & 2 \\
6) As cadeias carbônicas das moléculas de óleos são mais saturadas & 27 & - & 1 & 2 \\
ou insaturadas? & & & & \\
7) Qual a diferença entre óleos e gorduras? & & & & \\
\hline
\end{tabular}


8) Quais funções orgânicas são comumente encontradas nas moléculas presentes em gorduras trans?

9) O que são isômeros?

10) $O$ que são isômeros trans?

11) Qual a diferença entre isômero Cis e isômeros trans?

12) Nos alquenos isoméricos espacialmente, as duplas ligações podem existir de duas formas geométricas diferentes, quais?

\begin{tabular}{|l|l|l|l}
23 & 2 & 3 & 2 \\
21 & 5 & 3 & 1 \\
28 & 1 & 3 & 2 \\
18 & 6 & 4 & 2 \\
19 & 7 & 3 & 1 \\
22 & 2 & 2 & 2 \\
\hline
\end{tabular}

Com base nos resultados dos pós-teste, expresso na tabela 3, observou-se que os estudantes melhoraram significativamente seu rendimento referente ao tema abordado em relação ao pré-teste. Mesmo assim, alguns estudantes ainda deram respostas erradas ou não responderam. Esse fato pode ser atribuído a estudantes que faltaram à aula expositiva ou a segunda e terceira aulas ou não compreenderam bem o conteúdo abordado ou também as regras do jogo, sendo, portanto, constatado a relevância das duas metodologias para a melhoria do rendimento dos estudantes.

Finalizando, os estudantes perceberam a importância da utilização das atividades lúdicas para melhorar o aprendizado de alguns conteúdos da química, e que pode contextualizar a Química Orgânica, vários assuntos importantes no dia a dia, dos estudantes.

Diante dos resultados obtidos pôde-se perceber que o brincoquímica foi bem aceito pelos estudantes, pois ao complementar a aula teórica com exercícios e com jogos lúdicos, a mesma se tornou mais atrativa, divertida e interessante. Os resultados da avaliação dos estudantes com relação a aplicação do brincoquímica são demonstrados na tabela 4.

Tabela 4. Respostas dos estudantes para os questionamentos.

\begin{tabular}{|c|c|c|}
\hline \multirow[t]{2}{*}{ QUESTÕES } & \multirow[b]{2}{*}{ SIM } & \multirow[b]{2}{*}{ NÃO } \\
\hline & & \\
\hline 1- Os jogos auxiliaram na fixação do conteúdo? & $29^{*}$ & - \\
\hline 2-A aplicação dos jogos ajudou a melhorar os relacionamentos & 28 & 1 \\
\hline \multicolumn{3}{|l|}{ por ser uma atividade desenvolvida em grupo? } \\
\hline 3- A metodologia adotada é melhor do que uma aula expositiva? & 29 & - \\
\hline R. B. E. C. T., vol 8, núm. 1, jan-abr.2015 & & 5 \\
\hline
\end{tabular}

DOI: Em andamento 
4- Depois do jogo aumentou seu interesse em estudar mais o conteúdo da disciplina?

5- O jogo aplicado foi de fácil compreensão?

5- Trabalhando o conteúdo em grupo o jogo foi possível sanar algumas dificuldades?

Na última aula faltou um aluno

Ao responderem as questões propostas, 95\% dos estudantes concluíram que a aprendizagem é influenciada positivamente com a utilização de jogos nas aulas de Química e que a preferência em jogar em grupo, pode proporcionar interação do aluno-aluno, podendo contribuir, de acordo com Carvalho (2004) para melhorar o relacionamento entre os mesmos. E vai possibilitar o estímulo à participação, o interesse nas aulas e assuntos, induzindo o estudante a aprender de forma prazerosa, num contexto desvinculado da situação de aprendizagem formal.

\section{Considerações Finais}

Observou-se que, do total de 30 estudantes avaliados, quando questionados acerca da aplicação dos jogos para a sua aprendizagem, a grande maioria, considerou ótimo, pois havia reforçado os conhecimentos. A aplicação dos jogos despertou o interesse dos estudantes em estudar mais o conteúdo da disciplina, percebe-se que esta ferramenta didática promoveu entusiasmo em participar do jogo, motivando os estudantes a aprender mais sobre o assunto e a participar mais das aulas.

Pode-se concluir, portanto, que o jogo didático é uma ferramenta auxiliar e complementar para o processo de ensino e aprendizagem no Ensino de Química e que contribui para que o estudante de Ensino Médio se aproprie do conceito de ácido carboxílico, éster, isômeros, estereoquímica cis-trans, gordura, óleo, gordura trans, lipídios etc, através de uma ferramenta interessante e divertida.

Cabe destacar que os jogos pedagógicos não são substitutos de outras estratégias de ensino, mas se apresentam como uma ferramenta auxiliar/complementar no processo de ensino e aprendizagem, dando suporte ao professor, além de proporcionar a interatividade e o melhor relacionamento, tanto aluno-professor como também aluno-aluno.

A partir dos resultados obtidos pode-se afirmar que a introdução de jogos no cotidiano escolar é muito importante, devido à influência que os mesmos exercem frente aos estudantes, pois quando eles estão envolvidos emocionalmente na ação, torna-se mais fácil e dinâmico o processo de ensino e da aprendizagem. 
Após a aplicação dos jogos, muitos dos estudantes que demonstravam dificuldades, manifestaram satisfação com a atividade lúdica e compreensão acerca dos conteúdos abordados.

Espera-se que esta ferramenta lúdico-pedagógica cumpra seu papel, que é a melhoria da qualidade de ensino e da aprendizagem de conceitos da química orgânica, e por outro lado, seja um suporte didático para professores que já atuam no ambiente escolar, e para os futuros professores de química.

\section{Referências}

BENEDETTI FILHO, E.; FLORUCCI, A. R.; BENEDETTI, L. S. e CRAVEIRO, J. A. Palavras cruzadas como recurso didático no ensino da Teoria Atômica. Revista Química Nova na Escola, n. 31, 2009.

BORGES, R. M. R.; SCHWARZ, V. O. O Papel dos jogos educativos no processo de qualificação de professores de ciências. In: ENCONTRO IBERO-AMERICANO DE COLETIVOS ESCOLARES E REDES DE PROFESSORES QUE FAZEM INVESTIGAÇÃO NA ESCOLA, 4. Lajeado, RS, 2005.

CARVALHO, A. M. R. Jogos pedagógicos ou a gestão lúdica das necessidades. O Professor. III Série, n. 87, p. 26-29, 2004.

COSTA, M. J. A card game to teach the stereochemistry of carbohydrates. Journal of Chemical Education, 84, 6, 977-978, 2007.

CRUTE, T. D. e MYERS, S. A. Sudoku puzzles as Chemistry learning tools. Journal of Chemical Education, 84, 4, 612-613, 2007.

CUNHA, M. B. Jogos de Química: Desenvolvendo habilidades e socializando o grupo. In: ENCONTRO NACIONAL DE ENSINO DE QUÍMICA, 12, Goiânia (Universidade Federal de Goiás; Goiás), 2004. Anais, 028, 2004.

FERREIRA, W. M.; DO NASCIMENTO, S. P. F. Utilização do jogo de tabuleiro - ludo - no processo de avaliação da aprendizagem de alunos surdos. Revista Química Nova na Escola, v. 36, n. 1, p. 28-36, 2013.

GIACOMINI, R. A.; MIRANDA, P. C. M. L.; SILVA, A. S. K. P. e LIGIERO, C. B. P. Jogo educativo sobre a tabela periódica aplicado no ensino de química. Revista Brasileira de Ensino de Química, n. 1, p. 61-76, 2006.

HILL, M. M.; HILL, A. Investigação por questionário. Lisboa: Edições Sílabo, LDA, pp. 83-104, 2002.

MELO, C. M. R. As atividades lúdicas são fundamentais para subsidiar ao processo de construção do conhecimento (continuação). Información Filosófica. v.2 nำ1, p.128- 137, 2005.

NUNES, M. B. Jogos no Ensino de Química: Considerações Teóricas para sua Utilização em Sala de Aula. Revista Química Nova na Escola, v. 34, n. 2, 92-98, 2012. 
OLIVEIRA, A.S. e SOARES, M.H.F.B. Júri químico: uma atividade lúdica para discutir conceitos químicos. Revista Química Nova na Escola, n. 21, p. 18-24, 2005.

PARDAL, L.; CORREIA, E. Métodos e técnicas de investigação social. Porto: Areal Editores, pp.190193, 1995.

PIAGET, J. A Formação do Símbolo na Criança. Rio de Janeiro: Zahar Editores, 1975.

SANTOS, A. P. B. e MICHEL, R. C. Vamos jogar SueQuimica? Revista Química Nova na Escola, n. 31, 2009.

SOARES, M. H. F. B. e CAVALHEIRO, E. T. G. O ludo como um jogo para discutir conceitos em termoquímica. IN: Revista Química Nova na Escola, n. 23, p. 27-31, 2006.

SOARES, M. H. F. B.; OKUMURA, F.; CAVALHEIRO, T. G. Proposta de um jogo didático para ensino do conceito de equilíbrio químico. Revista Química Nova na Escola, n. 18, p. 13-17, 2003.

SOARES, M. H. F. B. Jogos para o ensino de química: teoria, métodos e aplicações. Guarapari: Ex Libris, 2008.

Carrascosa, J.; Gil-Pérez, D.; Vilches, A. e Valdés, P. 2006. Papel de la actividad experimental en la educación científica. Caderno Brasileiro de Ensino de Física, v. 23, n. 2, p. 157-181,

Delors, J. 2001. Educação: um tesouro a descobrir. São Paulo: Cortez; Brasília: MEC; UNESCO.

Fonseca, M. R. M. 2001. Completamente química. São Paulo: FTD.

Fourez, G. 2003. Crise no Ensino de Ciências? Revista Investigações em Ensino de Ciências, www.if.ufrgs.br/public/ensino/v8/n2.

Francisco Jr. W. E.; Ferreira, L. H.; Hartwig, D. R. 2008. Experimentação Problematizadora: Fundamentos teóricos e práticos para a aplicação em sala de aula de ciências. Química Nova na Escola, n. 30, p. 34-36.

Giordan, M. 1999. Experimentação no ensino de ciências. Química Nova na Escola, n. 10, p. 43-49. Hoffmann, J. Avaliar para promover: as setas do caminho. Porto Alegre: Mediação, 2001.

Mortimer, E. F.; Machado, A. H. 2002. Química para o ensino médio: volume único. São Paulo, Scipione.

Silva, R.B., Nóbrega, O. S., Silva, R. R. H. 2001. Química - Transformações e Energia. São Paulo: Ática,

Santos, W. L.P.; Mól, G. S (Coord.). 2004. Química \& Sociedade. São Paulo: Nova Geração.

João Rufino de Freitas Filho é Químico, Graduado em Licenciatura em Química, Mestre em Química Orgânica (UFPE), Doutor em Química Orgânica (UFPE), Pós-doutor em Química pela 54 DOI: Em andamento. R. Bras. de Ensino de C\&T 
Université Claude Bernard (França). É docente Universidade Federal Rural de Pernambuco UFRPE / Departamento de Química - DQ. Endereço para contato: Av. Dom Manoel de Medeiros, s/n, 52171-900, Recife, PE, Brasil. Telefones: (81) 3125-5674 ou (81) 8800-4928. E-mails: joaoveronice@yahoo.com.br.

Rinnely Cecília Lins de Melo é Química, Licenciada em Licenciatura em Química, Especialista em Ensino de Química pela Faculdade de Formação de Professores da Mata Sul - FAMASUL, Palmares/PE. É professora do ensino Médio da Escola Prof. Joaquim Augusto de Noronha Filho Barreiros - PE, Brasil. E-mail: rinnelylins@hotmail.com.

Juliano Carlo Rufino de Freitas é Químico, Graduado em Licenciatura em Química, Mestre em Química Orgânica (UFPE), doutor em Química pela Universidade Federal de Pernambuco. É docente do Centro de Educação e Saúde, Universidade Federal de Campina Grande, Olho D’água da Bica, s/n, 58175-000, Cuité, PB, Brasil. E-mail: julianocrufino@yahoo.com.br.

Ladjane Pereira da Silva Rufino de Freitas é Química, Graduado em Licenciatura em Química, Mestre em Ensino de Ciências (UFRPE), doutoranda em Ensino de Ciências (UFRPE). É docente do Centro de Educação e Saúde, Universidade Federal de Campina Grande, Olho D'água da Bica, s/n, 58175-000, Cuité, PB, Brasil. E-mail: julianocrufino@yahoo.com.br.

Jucleiton José R de Freitas é Químico, Graduado em Licenciatura em Química, Mestre em Química pela Universidade Federal de Rural de Pernambuco - UFRPE e doutorando em Química pela Universidade Federal de Pernambuco. E-mail: jucacleiton@yahoo.com.br 